\title{
EVALUATION AND PERFORMANCE OF BUSINESS
}

\section{Pickett*}

\author{
University of California, USA
}

\begin{abstract}
In this article, we've gathered a whole set of concepts and techniques to provide you with a presentation on how to evaluate assets, stocks, and business operations. We took the investor's point of view, valuing the value of the three major forms of securities issued by one company. Having covered the value and income in these situations, we expanded our eyes to cover the value of an existing business. Our goal was to find ways to determine the value of transactions such as a business sale, restructuring, or a combination of companies in the form of a merger or acquisition.
\end{abstract}

Key words: evaluate assets, stocks, business operations

We will start with some basic definitions of value in business circles. Then we will come to assess the value of the major forms of securities issued by the company from the point of view of investors. Finally, we will discuss the main issues of evaluating an existing business as a basis for determining the value of shareholders that we previously identified as the primary objective of modern management. As we have already pointed out, the relationship between cash flow and the creation of economic value is indicative of the success or failure of business investment, operation, and financing decisions.

\section{DEFINITION OF VALUE Economic value}

This concept relates to the main ability of an asset or right to provide cash flows from posttax to the holder. These cash flows can be generated through profits, contractual payments or partial or total liquidation at a future moment. Economic value is basically a concept of exchange. The value of each good is determined by the amount of money a buyer is inclined to abandon now - its present value in return for expected future cash flows. Economic value is therefore also a futureoriented concept. Economic value is determined by estimating potential future cash flows, including proceeds from the final placement of the good. It is recalled that the costs incurred by past decisions are costly and thus inexplicable from an economic point of view.

\footnotetext{
*Correspondence to: Dessislava Kostova-Pickett, Plovdiv, Str. Vasil Levski 3, Bulgaria, 0887674962
}

As we will see, economic value is at the root of some other common value concepts because it is based on the exchange that is quite natural to the investment process. However, the calculation of economic value does not come without practical difficulties. Recall that a typical discount rate must be selected and applied to the expected positive and negative cash flows for a certain period of time. These cash flows also include final value gains. The process in action determines the equivalence of the amount of cash flows that occur in different parts of the time spectrum.

Economic value is not absolute, but rather a criterion based on the relative risk assessment of future expectations. In fact, economic value is closely linked to individual risk preferences. Yet economic value lies at the heart of all business solutions for investment, operations and financing, whether these aspects are accepted.

\section{Market value}

It is also seen as a fair market price. This is the value of any asset or group of assets when traded on an organized market or between private parties in unimpeded unencumbered transactions. Securities and commodity exchanges are examples of organized markets such as literally thousands of regional and local markets and exchanges that allow buyers and sellers to find mutually acceptable values for all types of tangible and intangible assets. Of course, market value is also established through individual transactions when there is no proper organized market. 
PICKETT D.

There is nothing absolute about market value. Instead, it represents a momentary consensus between two or more countries. In a sense, the parties to a deal set their own estimates of the economic value of the asset enough to reach the consensus. Consequently, the market value at any one time may be the subject of the preferences and even the whims of the individual participants, the psychological situation prevailing in an organized exchange, the rise of a struggle for acquisition, the economic fluctuations, the development of the industry, the political environment and In addition, the current volume of trading in assets or securities will affect the value placed on them by buyers and sellers.

Despite its possible volatility, the market value as a whole is considered an acceptable criterion to be used to determine the value of individual assets and liabilities in the balance sheet. It is often used in inventory and analyzing equity investments in the form of future recoverable amounts. Mergers and acquisitions of operating entities are also based on market values established by the participants.

As is the case with economic value, there are practical problems relating to the calculation of market value. The true market value can only be found by actually participating in a deal. Thus, unless the item is traded, any market value assigned to it is only approximate and will tend to change along with changes in the terms and understanding of the participants.

But even if the market quotations are readily available, some conditions apply. For example, ordinary shares traded on major exchanges have significantly quoted market prices, and yet there is often price fluctuation even within one day. Thus, market prices that are based on very similar transactions can be fixed only within a range that is in turn bound by trading conditions for the day, week or month. For commodities that are rarely traded, estimating a realistic transaction value can be even more difficult.

\section{Book value}

The book value of an asset or liability is the announced price in the balance sheet that was recorded under generally accepted accounting policies. Although the book value is generally used for accounting purposes, it usually has little relation to the current economic value. Historical value is the one that in the past may have represented an economic value for the company, but over time and changes in economic conditions it is increasingly distorting it. This is especially true for the commonly quoted accounting value of ordinary shares that represents the shareholder's claim for the total outstanding balance of all past transactions in assets, liabilities and operations. Therefore, its usefulness for financial analyzes is questioned in most circumstances.

\section{Liquidation value}

This value relates to the particular situation in which a company must liquidate part of its assets and receivables. In essence, this is an abnormal situation in which time exerts pressure and even forces to distort valuations made by buyers and sellers. Under the cloud of overpriced business failure or strong pressure from creditors, management will understand that liquidation values are in most cases well below potential market prices. The economic environment is adversely affected by the known obstacle for the vendor participating in the transaction. As a consequence, the liquidation value is only applicable for limited purposes. However, it is sometimes used to estimate the value of the assets of unproven companies to perform an analysis of the credit assessment ratio.

\section{Partitioning value}

The variation in the liquidation value, the value of the split is related to the corporate takeover and restructuring. Assuming that the combined economic values of individual segments of a multi-business company increase the value of the company as a whole due to poor past management or ongoing capabilities that were not previously realized, the company will be divided into parts that will be available Other buyers to buy them. All unnecessary assets, such as the excess of real estate, are also sold for their current values.

Note that split-off value is typically realized in business segments, and is performed less frequently through violent liquidation of individual assets supporting these business segments. Surplus assets, of course, can be liquidated. Valuation of split value is a critical element in the analysis of previous takeover bids.

\section{Reproduction value}

This is the amount that is needed to replace an existing long-term asset in kind. In other words, this is the exchange price of a machine, skill or other similar asset. Reproduction value is actually one of several criteria used to calculate the cost of an existing business. The determination of reproductive value is an 
assessment that is largely based on engineering decisions.

There are several practical problems. The most important thing is whether the fixed asset in question can or could actually be reproduced just as it was originally created. Most tangible assets are subject to technological obsolescence over time in addition to physical wear and tear. There is also the problem of assessing the current current reproduction price of the good in kind. For the purpose of the analysis, the cost of reproduction is often only one step away from the valuation of the market prices of the assets of an active business.

\section{Value of collateral}

This is the value of an asset used for a loan guarantee or other type of credit. The amount of collateral is usually considered the maximum amount of credit that can be granted against a pledge of assets. Creditors, with their own point of view, usually determine the value of asset collateral lower than the market value. This is done to provide safety in the event of default and the individual risk preferences of individual creditors will determine the amount of the often arbitrary reduction. Where no market value can be easily estimated, the value of the collateral is established on a purely subjective basis and the creditor is in a position to allow as many safety margins as is considered advisable in the specific circumstances.

\section{Valuation value}

This concept of assessment is established in local legal situations as a basis for property taxation. The rules governing the valuation vary widely and can either take market value into account. The use of the valuation value is limited to the increase in tax revenues. In this way, such values are related to other value concepts.

\section{Estimated value}

The appraised value is subjectively determined and used when the asset has no clearly defined market value. In general, efforts are made to find evidence of transactions that are reasonably comparable to the asset being valued. It is often used in substantially large transactions, especially in commercial or residential real estate, and is determined by an impartial expert approved by both sides of the deal whose knowledge of the asset can reduce the distance that exists between the buyer and the seller or at least Build a range of bargaining. The quality of assessment depends on the valuer's expertise and the availability of comparable situations. Individual ability and preferences are included in the value. Only rarely different assessments will give the same result.

\section{Value of a going concern}

This is an application of the concept of economic value because a business that is viewed as a going concern is expected to produce a series of future cash flows that a potential buyer has to assess to reach a price for the business as a whole. Note that the same concept applies to business segments in the search for the split value. Regardless of the specific valuation technique applied here, the concept requires business to be viewed as a living "operating system" by operating parts rather than as a collection of assets and liabilities.

We have reviewed a number of value definitions. Many of them are directly or indirectly related to economic value. We have identified economic value as the present value of future cash flows discounted at the investor's risk-adjusted standard. This concept of value is widely applicable and we will use it by looking at different areas of decision where value measures are needed.

\section{VALUE FOR THE INVESTOR}

We will concentrate only on the three major types of corporate securities - bonds, preferred shares and ordinary shares - when looking at the techniques used to estimate value and yield. In this case, the value represents the current value of the investment for the investor in terms of the present value. Yield, in turn, is the internal rate of return (IRR) that the investor earned from a price paid for the investment. We will look at basic provisions in major types of securities only to the extent that they can affect their value and profitability.

\section{Bondable value}

Bond assessment is usually fairly easy. A typical bond issued by a corporation is a simple debt instrument. Its basic provisions in principle result in a series of contractual semiannual interest payments, defined as a fixed interest rate based on the declared nominal value of the bond (typically $\$ 1,000$ ). The legal contract or a duplicate agreement promises repayments of the principal (nominal value) on a certain maturity date over a certain number of years in the future. The main features of interest payments and repayment terms are found in the most common debt agreements. Sometimes complicating aspects exist in provisions such as conversion of ordinary shares at a predetermined exchange rate or interest payment only when earned by the 
issuer. We will briefly review some of these specified features. The base value of the bonds is based on the valuation that the investor makes to the relative attractiveness of the expected flow of future interest receivables and the prospect of a possible repayment of the principal at maturity. Of course, investors are usually not obliged to hold the bond until maturity because most bonds can easily be traded on the securities markets. However, the risk in the bond contract must be seen in terms of the ability of the issuer to generate enough cash to pay both the interest and the principal. Collective assurances of warranty analysts and investors about the prospects of the issuer to do so will affect the price level at which the bond will be traded publicly, and it is likely to be appreciated by financial services companies such as Moody's and Standard and Poor's, and will be Placed in a certain risk category associated with other bonds.

To determine the value of a bond, we need to calculate the present value of interest payments received by the maturity date and add the present value of the principal's final payment. The applied discount rate is the regulated risk, which is the investor's own standards for assessing investment opportunities within an acceptable risk.

For example, an investor with an $8 \%$ return on an annual basis will rate one bond with a coupon rate of $6 \%$ a year significantly lower than its nominal value. The annual return of $8 \%$ of the investor is equal to the half-yearly standard of $4 \%$. This is a recalculation for the purpose of the calculation, which is necessary to coincide with the half-year interest payments from most bonds.

The resulting value, $\$ 832.89$, represents the maximum price our investor must be willing to pay - or the minimum price the investor should be willing to sell - if he usually expects a return of $8 \%$ of this type of investment. Therefore, specifically, this bond must be acquired only at a price relatively below the nominal value. Note that the announced bond rate is only relevant when determining halfyearly cash proceeds in absolute dollar terms.

The actual assessment of the bond and the cash flows it represents depends on the degree of opportunity (return standard) of the investor. In other words, the desired profit determines the price and vice versa. This relationship, of course, is also applicable to market quotations of publicly traded bonds. The quoted price or value is a function of the current yield that is desired by many buyers and sellers of these debt instruments.
If our investor, for some unrealistic reason, is not satisfied with the very low annual yield of only $4 \%$ because he owns the same bond (equal to $2 \%$ over a six-month period), the value for the investor will significantly exceed the nominal value. In these supposed circumstances, the investor must be willing to pay a premium of $\$ 212.43$ for the $\$ 1,000$ bond because the personal return standard is lower than the stated interest rate. If the investor's own standard and the coupon rate were exactly the same, the bond's value would, of course, match the face value of $\$ 1,000$.

In fact, the quoted market price of each bond will tend to approach the face value until it reaches maturity, because at this point the only representative value will be the forthcoming principal payment - assuming, of course, that the company is financially capable of paying when The amount becomes due.

Bond yield. A related but common problem for the analyst or investor is the calculation of the yield generated by different bonds when quoted prices differ from the nominal value. The key to this analysis, again, is the relationship between value and return, as we have seen. The approach used is the calculation of the present value, which in practice determines the internal rate of return of the cash flows generated by the bond over the remainder of its life cycle.

The method is identical to that used in the cash flow estimation for each business investment proposal. The key difference in data is that individual investor calculations are based on pre-taxing cash flows that have to be adjusted in each case by the investor for the individual situation. Other minor differences are the spread of available cash for the half-year and the form in which bond prices (net investment) are quoted. The published prices are usually declared as a percentage of the nominal value. For example, a bond quoted at $103 \%$ has a price of $\$ 1,033.75$.

Bond yield tables have long been used to determine the internal rate of return (yield) of a bond. Although today's computers and calculators have financial programs that allow direct calculation, we'll take a look at a profitability chart, even to help the reader understand examples through visual link analysis. Bond yield tables are some wellmatched present value tables that contain the entire potential range of reported interest rates subdivided into partial increments of up to $1 / 32$ of a point. 
The yield to maturity can be estimated approximately using a quick method if neither a programmed calculator nor a bond table is at hand. Assuming our 6 percent bond is quoted at $\$ 832.89$ on July 1,2016 , the $\$ 1,000$ face value rebate is $\$ 167.11$. In this way, the investor will not only receive the $\$ 30$ coupon rate for 28 periods, but will also receive a $\$$ 167.11 rebate if the bond is held to maturity and if the $\$ 1,000$ pay out is received.

The quick method calculates approximately the true yield by adjusting the periodic interest payments with a proportional amortization of this rebate. The first step reflects the usual accounting practice of amortization of discounts or bonuses over the life cycle of the bond. In our example, the $\$ 167.11$ rebate is divided into the remaining 28 periods, and the

$$
\text { Yield }=\frac{2 \mathrm{x} \$ 35,97}{\$ 916,45}=7,85 \% \text { per year }
$$

This result is slightly below the exact yield of $8 \%$ per year. The averaging quick method will always provide some errors because it simulates the progressive structure of the current value. With the increase in yield rates and the number of periods, larger errors will also occur. However, rough calculation provides a satisfactory result when used as an initial analytical check.
$\$ 5.97$ periodical incremental period is added to the $\$ 30$ periodic interest earnings. The adjusted six-month earnings are now \$ 35.97 per period.

The next step relates the adjusted periodic earnings of $\$ 35.97$ to the average outstanding investment over the remaining life of the bond. The paid price of the investor is $\$ 832.89$, while the cost of the investment will increase to $\$ 1,000$ to maturity. The average of the two values is half the amount, $\$ 916.45$. Then we can calculate the periodic return to maturity (based on the 6-month interest period) by linking the periodic earnings of $\$ 35.97$ to the average unpaid investment, or we can find the annual yield to maturity by linking two 6month earnings volumes of $\$ 35.97$, each up to the average investment:
If a premium was included (in other words, if the purchase price is above the nominal value of the bond), the direct method of calculation will reduce the periodic interest yields with the proportional amortization of the premium.

The result will be as follows, again returning an approximate sum of the actual 4-percent equation:

$$
\text { Yield }=\frac{(\$ 30.00-\$ 7.59) 2}{((\$ 1,212.43+\$ 1,000) \div 2)}=4.05 \% \text { per year }
$$

Bond yield calculations include a relatively easy determination of an internal rate of return on future cash flows generated by bond investments at a known current price. As for capital business investments, replace current expenses for future cash flows in uncertainty. Yield and value are mathematically linked, and this relationship can be used to detect or result in predefined bond yield tables, or to allow analysis directly with a programmed calculator or PC.

Bonding and value. Ordinary value and yield relationships discussed so far are, of course, influenced by the specific circumstances surrounding the company and its industry and also by the additional provisions set out in the Bonds Agreement itself. The investor's solvency needs to be assessed by carefully analyzing the company's profits and anticipating the expected results. Solvency is a function of the forecasted cash flows and how much these flows cover the servicing of the interest and principal debt. A sensitive analysis based on high and low performance estimates can be useful in this case.

Changes in the terms of the bond will also affect the earned value and profitability. Here we will only consider the main types of bond changes. Mortgage bonds are secured by certain assets of the issuing company. Because of this link bondholders have relief against the principal's default. As a result of the reduced risk, the coupon rate offered with the mortgage bonds may be slightly lower than that of the unsecured long-term bonds and reduce the return on the investor. Bond yields are the other extreme of the risk spectrum because they are not just unsecured but also pay interest only if the company's profits reach a certain minimum. Yield rates will be just as high.

Convertible bonds give attractiveness to the potential stakeholder participation in the potential market valuation of ordinary shares against which the bond can be exchanged for a certain price. Therefore, the coupon rate may be slightly lower than that of traditional bonds. The value of convertible bonds is influenced 
by (1) the market estimate of the probable performance of ordinary shares, (2) the difference between the agreed conversion value and the current price of ordinary shares, and (3) the coupon interest paid half-yearly.

Typically, the conversion price is higher than the prevailing market value of ordinary shares at the time of issue to allow an expected increase in the value of ordinary shares over time. Conversion is, in principle, at the discretion of the advertiser when deemed to be advantageous, although the contract usually provides for a deadline and the right of the issuer to declare the redemption bonds at a slightly higher price after a given date Way forcing the investor to act. When ordinary stock prices converge and exceed the conversion price, the value of the bond will exceed the nominal value due to the growing value of the equivalent ordinary shares it presents.

A relatively recent phenomenon in bond markets is the emergence of so-called high-risk bonds that are widely spread by some investment bankers to help absorb by using very high levels of debt or so-called " Loan buyouts by management groups, or investors who, in a similar way, use extremely high leverage to finance the purchase of the company. These securities are in fact subject to creditors' claims in the event of a default and are sold in often high-risk circumstances because the level of indebtedness in some of those transactions exceeds what is normally considered reasonable. The yields on these unsecured instruments are in fact proportionate to the high risk perceived by investors, and penalties are not uncommon.

Many other modifications and provisions are possible to adapt the various bonds to the needs of the issuer company and to the prevailing conditions of the securities markets. The many variations in bond arrangements and their effect on value and profitability require careful judgments that go beyond the direct analytical approaches already under consideration. We reiterate that the calculations considered are only the starting point and there are no strict rules for the mechanical weighting of the value of the bonds. In the final analyzes, the value and yield should be adjusted taking into account the investor's economic and risk preferences in accordance with the specific purposes of holding debt instruments.

\section{Preference Share Values}

In essence, preferential shares represent the medium between debt and equity. The warranty provides a series of cash dividend payments, but usually there is no definite assurance (or expectation) of paying the nominal value of the share. Sometimes, however, preference shares allow the issuer to withdraw a portion of the shares over a certain period by paying small amounts over the stated value of the share.

Although the investor has a preferential position on ordinary shares in terms of current dividends and also with a repayment of the principal in the event of liquidation of the entity, preferential dividends may not be paid if the company's performance is weak. Such an event, of course, will have an adverse effect on the value of the share.

Preferential dividends, just like ordinary dividends, are announced at the discretion of the board of directors, and if they are absent, they may not create them unless preferential issues do not impose certain legal requirements to the contrary. Such provisions may, for example, require the collection of past unpaid dividends, while the company can now afford to declare any dividends. In other cases, especially in new companies, preference shares may have an element of participation that requires the board of directors to declare preferential dividends higher than the stated rate if profits exceed the minimum. But these two particular situations are rare.

Therefore, the task of calculating preference shares should be based on less defined conditions than in the case of bonds, because the only relatively certain element is the declared annual dividend, which is defined as a percentage of the declared value. For example, a $8 \%$ preference share typically refers to a $\$ 100$ share, which is expected to pay a dividend of $\$ 8$ a year, most likely in quarterly installments, a model typically resembling that of ordinary shares. The investor has to cope with the calculation of this flow of future cash dividends. If the price paid for a share of preference shares is $\$ 100$ and the share is held indefinitely, the yield under these circumstances will be 8 percent and we can assume that the company is likely to be able to pay the dividend on a regular basis.

If the price is greater or less than the declared value, yield can be found by referencing the amount of the dividend to the actual share price:

$$
\text { Yield }=\frac{(\text { Annual Dividend per Share })}{(\text { Paid Price per Share })}
$$


If the investor can expect to sell the $\$ 100$ share for 5 years, we can determine the exact yield using either current value approaches or direct methods.

However, the calculation of a future liquidation value involves many assumptions. Unlike bonds, preference shares do not have a fixed maturity date or face value to be paid to maturity. The real price of a preference share traded on the securities markets depends on the company's performance and on the total value these markets give to the preference share. In response, the price level reflects the risk / profit swap that is required for the full range of investments currently. The value range will depend not only on the respective risk premiums assigned to the individual securities but also on the inflation expectations in the economy that are reflected in the non-risk rate

$$
\text { Value for Share }=\frac{\text { Declared Rate of Dividend })}{(\text { Search Return })}=0.08 / 0.09=\$ 88.89
$$

If the investor is satisfied with only $7 \%$ return, the value will be:

$$
\text { Share Value }=\frac{0.08}{0.07} \$ 114.28
$$

The decisions to be taken, of course, are related to any uncertainty about the future dividend model and any material change in the future value of the share due to changing market conditions or a scheduled call for redemption of a higher Price.

\section{Preferential commodity regulations and} value. As far as bonds are concerned, there are many changes to the provisions on preference shares that may affect their value on the market. We previously mentioned that some preference shares, especially in start-ups, contain an element of participation that gives the holder of the preference greater dividends if corporate profits exceed the specified level. This feature may have a positive impact on potential returns and thus on equity valuation, depending on how likely the company is to reach this higher profit level.

A much more common feature, similar to some bonds, is convertibility. This is the opportunity to change the preferential position of the owner in that of ordinary shares. In Convertible Bonds, however, the value of this characteristic cannot be calculated accurately. However, when the ordinary share price reaches and exceeds the announced conversion price, the price of the convertible preference share will tend to reflect the market value of the equal number of ordinary shares. Before that happens, the value of the convertible preference share will generally be considered the same as the value of the ordinary preference share will be based primarily on the declared dividend. Convertibility is usually accompanied by a buy-back provision at a higher price. This allows the company to force a conversion under the right conditions.

The challenge in calculating preference shares goes beyond the simple approaches we have shown. Finally, decisions must be made after careful consideration of the relative attractiveness of the specific features and conditions surrounding the preference shares of a company.

\section{Value of ordinary shares}

The most complex problem arises when it comes to ordinary shares because, by definition, the ordinary share represents the residual right of the owners on the full productiveness and prospect of the issuing stock corporation.

Determining the price of ordinary shares is particularly difficult because it involves a property risk, but it does allow for both the asset and the earnings right after all other claims are met. In this way, investment in ordinary assets involves the sharing of both risks and revenues. This increases the uncertainty of future dividends and the repayment of the principal. As a result, measurement techniques are used to deal with those variables that are difficult to determine.

Earnings from the holding of ordinary ordinary shares are several: cash dividends (and 
sometimes additional share distributions instead of cash), growth in subscribed capital (partially reinvested by management), as well as past and future cash flows with The increase (or decrease) in the price of the stock exchange.

Profit and cost of ordinary share. The easiest way to determine the value of a share of ordinary shares is to determine the future profit level per share and to focus on those earnings with an appropriate discount rate that reflects the expected return on the risk assumed by investors.

The formula is:

$$
\text { Share price }=\frac{\text { earnings per share }}{\text { discount rate (expected return on investors) }}
$$

A more specific approach to determining the value of ordinary shares is to focus on the expected dividends. The size, regularity, tendency to pay dividends to shareholders has an important effect on the cost of ordinary shares because they are elements of attracting investors. However, there is a degree of uncertainty about obtaining any future dividends. Such dividends depend not only on the company's ability to successfully present itself on the market but also on the disclosure by the board of directors.

There is no general rule applicable in this area - dividend distribution policies may range from not paying to payout to $75 \%$ or more of current earnings. Sometimes dividend payments may even outperform current earnings because the company does not want to reduce the current payout of dividends per share during a temporary downgrading. Most board boards consider it important to pay dividends on a

$$
\text { Value per Share }=\frac{\text { Current Dividend }}{\text { Discount Rate (Expected Return on Investors) - Dividend Increase Rate }}
$$

This specific formula is based on the idea that the value of the shares is the sum of the present value of a series of increasing annual dividends reduced by the expected return on the investors for a particular risk. But this implies a series of constantly growing payments and a constant annual rate of growth of dividends paid. The formula also allows the use of less realistic assumptions about steadily declining dividends.

\footnotetext{
Return on ordinary share and expectations of investors. Two simple criteria for measuring the return on equity investors are presented. One of them is earnings, just a ratio of current or planned earnings per share to the current market price. The other is feedback, the so-called Price / profit ratio. These simple ratios are a static expression based on the prepared information and should serve as a temporary rough indicator of the true return on investment created by the company's economic performance.
}

permanent basis, and large changes in dividend sizes are reluctant.

The dividend valuation approach involves forecasting expected dividends and discounting them from the expected standard appropriate to the investor. Here are some major issues.

First, the current level of dividends paid will probably change over time. The second problem is the calculation method. The most common format is so-called. A model of the declining dividend or a pattern of increasing dividend that we will look at in its simplest form. In this approach, we have determined the cost of net worth as the ratio of current dividends to the current market price + the expected growth rate of future dividends. So instead of finding a solution to net worth, which is the expected return on investors, we find a solution to the value or price of the share:

The two measures are mainly useful for benchmarking of companies and industrial groups but need to be supplemented by more insights if analysts want to specify the exact economic return on equity. For each serious value or return analysis, asset valuation considering the market risk, the company's specific risk and the shareholders' preferences.

Many studies have improved our understanding of the relative performance of ordinary shares on the market. As a result, the definition of the systematic guarantee is improved, this model links the risk-weighted exposure risk to the market portfolio risk by means of the calculating factor $b$ which shows the difference in the risk characteristics of the shares and the risk characteristics of the portfolio. They are determined in terms of historical trends that have no risk-taking form of return as well as the safest type of investment, namely long-term government securities. 
Thus, the expected return on ordinary share is the sum of the risk-free return + the additional risk, as is the additional risk of the total portfolio of shares, corrected by the inherited risk of the specified guarantee:

$$
\text { Return }=\mathrm{Rf}+\beta(\mathrm{Rm}-\mathrm{Rf})
$$

Where:

$R f$ is without the risky form of return

$\beta$ is a specific measure of risk

$R m$ is the expected average return on ordinary shares

Fortunately, $\beta$ for publicly traded companies is readily available in financial services such as Value Line. Risk-free rate indications are widespread at this time, and return-to-equity ratio calculations are also available in published sources.

We have just touched on some of the techniques used to determine the value and return of ordinary shares. There is a much greater practical and theoretical insight to deal with the complex issues that are involved.

Other Considerations in the Measurement of Ordinary Shares. The book value of ordinary shares is often mentioned in financial sources and company reports. As we have seen, this value is the registered residual claim of the shareholders, as recorded in the balance sheet. The book value is a sum of previous values and does not reflect the economic value in the form of future profits or dividends. Only under unusual conditions the book value of a share would accurately represent the economic value of the share of common shares.

This may be true when, for example, a company is already established or is about to be liquidated. Under normal circumstances, however, the book value of the share will move away from the current value because changes in the value of current assets are rare, but when they occur, they are reflected in the adjustments of the books. A book value that approaches or even exceeds market value indicates that the troubled company is ineffective. This is a situation that prompted aggressive investors or corporations to attempt to swallow.

Suffice it to say that if the following conditions are met, the quote of the stock market share may be assumed to fulfill its economic value based on the current and future performance of the firm.

- Action must be sold often in a relatively large volume.

- Unit ownership must be allocated so that the sale does not involve the shifting of large stakes among a small number of interested groups.

- The action must be publicly sold on one or more exchanges or be part of the gaining importance over the stock market.

Even if all of these conditions are met, the value of the stock exchange at any one time may not reflect the real potential of the company because external factors (such as changes in the economy, market conditions, company publicity and its industry, or take-up attempts) To reflect the price at which the share is being sold. To help them understand this content, analysts examine the extent to which market prices change, preferably at least over a year.

\section{ASSESSMENT OF CURRENT BUSINESS}

It is often necessary to find the full value of business as a current unit, especially when considering its purchase or sale, but also to determine changes, value and time. Such a type of valuation can be used when a company for internal restructuring needs is deprived of certain defined product lines or a work department. Buyers may be other companies, groups of investors, or even existing management, wanting to acquire a fund funded by large buyouts using large proportions of unsecured debt.

Regardless of the form of sale, purchase or restructuring, both the buyer and the buyer must reach a reasonable approximate sum of the economic value to the business. At the same time as the owner and the rulers have a continuous interest in the current and expected value of the business even if no sale or merger is considered. Managing economic value has become an important focus nowadays.

First, we will discuss the key concepts of business cash flow assessment that is applied in most evaluation situations, then we will focus on more specialized restructuring cases and the value of corporate takeovers, and at the end we will consider the absolute managerial obligation to create Value for shareholders.

Cash flow assessment in business

In fact, the current business is a series of future cash flows. Thus, the methods for determining the present value are applicable here, just as the analyst has calculated the desire for monetary investment. This desire to transform past and forecasted earnings that await profits in the form of net cash flows.

Let's start with the net profits of business predicted for a reasonable number of years in 
PICKETT D.

the future. The corresponding definition of operating earnings is a profit before interest but after taxes it is (EBIT). The reason for using this model is that we are looking for the cash flows generated before any financial rewards.

Designing expected earnings requires a variety of assumptions and judgments. The easiest way to design, however, would be to look at the current level of profits as a constant. In most circumstances, such simplification cannot be realistic. If operating profits are expected to increase or decrease, or to follow a cyclical pattern, we need to make annual design as long as possible in the future. Any significant nonoperating profit after deduction of taxes, such as investment income, should be considered and added in each period because they are part of the value of the entire company.

The second step is to turn operational profits into cash flows by adjusting profits after taxes, which results in deduction of depreciation costs.

The third step is to determine future capital costs needed to maintain both the current revenue level and the expected changes in operations. This includes property costs, equipment, program costs, development and research projects, and partially capital requirements.

To some extent, these estimates are quite speculative because it is not, in principle, realistic to assume that current business revenues will continue to rise to the current level. Undoubtedly, there will be periodic infusions of replacement capital with improvements to current equipment without mentioning requirements to maintain the expected growth.

The final step in assessing the current business involves reflecting analyzes after a certain number of years and extracting the terminal value (market value) of the business for that period. By definition, this terminal value is the sum of the present value of all future cash flows after this period. What is difficult in prediction of operations after the end of an analyzed period requires a direct response to the terminal value.

A common way to deal with the problem is to use the multiplied simple earnings for that period. This is done to determine the value of a business for 6 or 10 years, or for what specific period we want at 8,10 or 15 times after the tax profits for that year. The choice of multiplier depends on the nature of the business and on the industry trends that, due to the devaluation force, such an approximate amount of terminal value would be satisfactory.

The annual net cash flows, called free cash flows, are the cash available to the company to support its obligations and to provide longterm financial resources (for example interest payment, dividends, potential debt repayment or even redemption of own shares).

Once the annual model + Terminal value is impaired with an appropriate return - usually the value of the equity - the net present value received represents a fair approximate amount of the value of the current business. The quality of the outcome depends, of course, on the quality of the budget assumptions used in its extraction. The analyst must use sensitive analysis to test the likely range of results.

It is useful to visually demonstrate how this current value relates to the company's capital structure. What we received with the devaluation of net cash flows and the assumed terminal amount is the approximate market value of the company's capitalization.

It should be clear that in order to arrive at the market value of the shareholder's equity we must deduct the value of the long-term debt from the current value, which is the total market value of the business called the value of the firm or the value of the enterprise. We need to be careful when determining the value of long-term debt not in terms of the recorded value in the balance sheet but in terms of current yield.

Thus, if the current interest rates are higher than the indicated percentages in the debt of the company, the value of the debt will be lower than the subscribed and vice versa. By observing this principle, we are in line with the following charge price applied to the cash flow depreciation - a measure that shows the cost of the partial debt. Such a reduction should be made for each preferred share contained in the capital structure.

In this way, we achieved a direct valuation of the ordinary shares of the company with an economic approach that surpasses the simple mechanisms we looked at in the ordinary shares section. This idea is fundamental to many analytical developments that underline the modern analysis of guarantees where the cash flow analysis overshadows most other methods.

In a multifaceted company, the approach can 
be improved by developing cash flow management for each business unit and devaluing these individual models at the expense of corporate capital costs or if the business differs sharply in its risk / profit conditions, various discount Standards that reflect these differences. In recent years, the concept of testing the present value of individual business units to determine the relative share of the total value of the corporation was widely accepted.

Still, given the nature of the assumptions underlying the analysis, there is nothing automatic to apply such values in a real deal relating to the sale of a company or one of its components and parts. Various analysts and some buyers and sellers will use their own assumptions in developing relevant results. Efforts will be needed to test the analytical results of a comparable transaction to the extent that they are available and appropriate. The actual value finally accepted in a deal between a seller and a buyer will depend on many other factors, not least the difference in expected returns between the parties involved and their negotiating positions and skills.

\section{Value in restructuring and mergers}

This article will apply the concepts of analyzing cash flows of an operating business and related measures to the specific problem of restructuring a company for higher value or looking for a higher value when merging two or more companies.

Restructuring and value. The possibility of restructuring arises at the request of the management or interested external parties where there is a difference in the value between the value achieved by a company and the potential one achievable under changed circumstances. This difference in value, in simple terms, represents the difference between the present value of future cash flows under current circumstances and the present value of different and substantially larger cash flows from the restructured company. The attraction of corporate take-over is if the company realizes the potential hidden benefits of this difference in value. Depending on the circumstances, the difference in value may require significant bidding premiums for prices commonly encountered in takeover situations although the final results may be lower than the premiums paid in the competition process.

From an analytical point of view, the approach is similar to the current cash flow assessment that we have already discussed. The main difference is that a set of ratings is used that identifies specific improvements in the cash flow model, as well as the liquidation value of businesses or redundant resources.

If the previous analysis can be defined as

$$
\text { Value }=\text { PV }(\text { Free Cash Flow }+ \text { Terminal Value }
$$

then the restructuring approach can be defined as

$$
\begin{aligned}
& \text { Value }=\text { PV }(\text { Free Cash Flow }+ \text { Terminal Value })+\text { PV (Improvements })+ \\
& \text { PV(Liquidation income - Liquidated cash flows })
\end{aligned}
$$

and the difference in value will be the difference between the two results. A key temptation for the restructured firm is, of course, taking control of the associated higher cash flows.

Mergers and synergies. Another form of restructuring is found in combining two or more independent companies. The common cause of acquisitions and mergers is that economic benefits from synergy can be expected. While many empirical studies have cast doubt on whether business mergers are always beneficial to both parties, it is logical to assume that joining two separate businesses, especially in the same industry, will contribute to some operational efficiencies.
The impact of synergy can be felt in two main ways. Most direct benefits are visible cash flow improvements, or, in particular, lower costs stemming from consolidation and equipment and staff reductions, and higher benefits from improved market position and coverage. The specific levels of such cash flow benefits should be predicted when an absorption or merger is contemplated. Such forecasts, of course, will vary in quality, depending on how measurable the opportunities for improvement are. Tax and leverage effects can also occur, as discussed in the previous chapter.

Mergers and equity values. When an exchange of ordinary shares is included in a merger or acquisition agreement, the 
PICKETT D.

assessment challenge expands beyond the economic assessment of the cash flow models. The problem of the valuation of two different bonds appears, and the problem of finding an appropriate exchange ratio that reflects the value of the units. Moreover, in most cases, the recipient has to pay a substantial premium (between 15 and 25 percent is the usual amount) on the company's objective value.

While two shares are valued, any differences in the quality and breadth of trading in the securities market can be an important factor. If, for example, a large and well-established company acquires a new, fast growing company, the market valuation of the shares of the receiver is perhaps more reliable than that of a newly-acquired company whose shares may be rarely traded and unproven. But even if they had such a market scope, the inherent difference in the type and performance of the two companies may be a significant difference in price / profit ratios. In practice, this means that the performance of a company is less well appreciated in the market than the other. This difference will affect the valuation of the shares and the negotiation of the final price.

\section{Management of shareholder value}

The most complex and empirically-based methodology of this type was developed by HOLT Value Associates, a subsidiary of the Boston Consultative Group. Its value-based management system is based on translating a company's financial performance through multiple adjustments to a current dollar monetary return on investment measure (CFROI) that expresses the company's economic performance. This concept, applied to expected cash flows and combined with forecasted growth in the company's assets, can be used to calculate the market value of the company by applying a market-based return on investment standard. This model recognizes the contribution of the adjusted cash flows from existing assets and links them to new investor cash flows, all of which have a similar economic base.

The main message of governance for shareholder value is nothing more than the duty of management to base all its investment, operational, and financial decisions on economic logic and to manage all resources left under its control in order to achieve better economic returns. Over time, the persistence of this approach will generate growth in shareholder value and growth in share price depiction, dependent on the movement of the overall stock market. important tool for analytically oriented people with any view that appreciates the performance and prospects of any business.

\section{KEY QUESTIONS}

The following is a summary of the key questions raised directly or indirectly in this article. They are listed here to help remember the techniques that were discussed in the field of financial theory and business practice.

1. The challenge of evaluation includes the two issues of predicting the economic benefits derived from an asset and that of choosing an economic standard to measure these benefits.

2. Value takes many forms, but in the end business valuation should be based on an attempt to express the risk / profit ratio in the form of the involved cash flows and the generated ones.

3. Investors are approaching the evaluation of an investment proposal in terms of their individual risk preferences. Consequently, market values are a function of individual and collective risk assessments.

4. Evaluation techniques are basically assessment tools that attempt to quantify the available objective data. However, such a determination will always remain partly subjective and partly subject to forces beyond the control of individual countries.

5. While the securities market provides shortterm indicators, the value of a common share at any time of a combination of residual claims, future expectations, and an assessment of the underlying and specific risk subject to economic and business conditions and the management's decisions and the board of directors.

6. Evaluation is distorted by the same elements that distort other types of financial analysis: changes in price levels, accounting conventions, economic conditions, market changes and many other subjective intangible factors.

7. Assessing a business for sale or purchase is one of the most complex tasks for an analyst. It requires skills in predicting profits and cash flows, risk assessment, and interpretation of the impact of combining management styles, operations, and resources.

8. Creating shareholder value is the ultimate result of successful investments, operations, and funded executed by management in an economic structure. However, the relationship between present and projected performance of a company in these areas and the market value of its ordinary shares over a given period is not directly or directly measurable due to the combination of stock market forces.

Financial analysis in its many forms is an 


\section{SUMMARY}

In this article, we've gathered a whole set of concepts and techniques to provide you with a presentation on how to evaluate assets, stocks, and business operations. We took the investor's point of view, valuing the value of the three major forms of securities issued by one company. Having covered the value and income in these situations, we expanded our eyes to cover the value of an existing business. Our goal was to find ways to determine the value of transactions such as a business sale, restructuring, or a combination of companies in the form of a merger or acquisition.

We have found that methods are available to retrieve such values, but also that specific assumptions and transaction history add many dimensions to the underlying calculations. Finally, we discussed the concept of shareholder management, returning to a review of the systems linking management decisions on investments, operations, and financing to the present value of a business, and then linking shareholder value to dividends and capital increase. After all, the value will always remain partially subjective and will be established in the exchange between stakeholders, but governance for economic growth and value is seen as the core duties of management.

\section{REFERENCES}

1. Boston Consulting Group.Value Based Management:A Framework for Managing Value Creation. Chicago: Boston Consulting Group, 1993.

2. Brealey, Richard, and Steward Myers.Principles of Corporate Finance. 3d ed. New York: McGraw-Hill, 1988.

3. Copeland, Tom; Tim Koller; and Jack Murrin.Measuring and Managing the Value of Companies. New York: John Wiley \& Sons, 1990.

4. Pratt, Shannon P. Valuing a Business: The Analysis and Appraisal of Closely Held Companies. $2^{\text {nd }}$ ed. Homewood, Ill.: Dow Jones-Irwin, 1989.

5. Rappaport, Alfred. Creating Shareholder Value. New York: Free Press, 1986.

6. Rock, Milton R. The Merger and Acquisition Handbook. New York: McGraw-Hill, 1987.

7. Rosen, Lawrence R.The Dow Jones-Irwin Guide to Calculating Yields. Homewood, Ill.: Dow Jones-Irwin, 1985.

8. Van Horne, James C. Financial Management and Policy. $9^{\text {th }}$ ed. Englewood Cliffs, N.J.: Prentice Hall, 1991.

9. Weston, J. F., and Eugene Brigham.Essentials of Managerial Finance. $10^{\text {th }}$ ed. Fort Worth, Tex.: Dryden Press, 1993. 